POLLACK PERIODICA

An International Journal for Engineering and Information Sciences

DOI: $10.1556 / 606.2017 .12 .3 .4$

Vol. 12, No. 3, pp. 33-42 (2017)

www.akademiai.com

\title{
EQUIVALENT UNIQUE GLOBAL AND LOCAL INITIAL IMPERFECTION - IMPERFECTION IN EN 1993-1-1 AND EN 1999-1-1 CLAUSE 5.3.2 (11) - CALCULATION PROCEDURE AND DISCOVERED OBSTACLES
}

\author{
Ján BRODNIANSKY \\ Department of Steel and Timber Structures, Faculty of Civil Engineering \\ Slovak University of Technology in Bratislava, Radlinského 11 Bratislava \\ Slovakia, e-mail: jan_brodniansky@stuba.sk
}

Received 30 December 2016; accepted 1 May 2017

\begin{abstract}
Equivalent unique global and local initial imperfection is introduced in standards EN 1993-1-1, EN 1999-1-1 in clause 5.3.2 (11) and in Slovak national annex to EN 1993-1-1 NB. 5. However approach described in these standards needs further explanation to fully understand its background to reduce possibility of causing errors. Equivalent unique global and local initial imperfection and derived equivalent unique global and local initial imperfection method is based on obtaining amplitude for structural buckling mode, which can be than used as full-sized imperfection in assessment of structures loaded by combination of axial compression forces and bending moments. Equivalent unique global and local initial imperfection was firstly used and introduced by prof. Eugen Chladný from Slovak University of Technology in Bratislava. The origin of this method was based on the need of assessment of upper chords of open-deck truss bridges. The main idea is described in detail by Prof. Eugen Chladný and Magdaléna Štujberová in paper in magazine Stahlbau vol. 82. Equivalent unique global and local initial imperfection method in mentioned standards and paper is designated for plane structures like simple structural members or frame structures. This paper examines in plane behavior of structures with presented imperfection and calculation procedure, which allows fast examination of many different types of plane structures.
\end{abstract}

Keywords: Imperfection, Equivalent unique global and local initial imperfection, EN 1993-11 5.3.2 (11), EN 1999-1-1 5.3.2 (11)

\section{Introduction}

According to the standards [1], [2] and clause 5.3.2 (11), it is possible to use the elastic critical buckling mode as an imperfection and determine the amplitude of this 
imperfection. Imperfection is called Equivalent Unique Global and Local Initial imperfection (EUGLI imperfection). The whole calculation procedure is done according to the $2^{\text {nd }}$ order theory with EUGLI imperfection and it is called EUGLI imperfection method. The whole theoretical background of EUGLI imperfection was published in [3]-[7]. Because of complexity of the solved problem, a computer program was developed in MATLAB programming language [8]. Some descriptions that include computer program background can be found in [9], [10]. This paper presents a relatively new matrix calculation procedure (mass iteration method) of EUGLI imperfection method.

The most important formulae described in [1], [2] clause 5.3.2 (11) is in (1). $\eta_{\text {init,m, max }}$ represents the amplitude of the EUGLI imperfection in the shape of the elastic critical buckling mode. Index $m$ denotes critical cross-section (critical cross-section parameters are used for calculation of EUGLI imperfection amplitude) on the structure by means of EUGLI imperfection method and position of this cross-section is estimated by means of iterative approach,

$$
\eta_{\text {init }, m, \max }=e_{0 d, m} \frac{N_{c r, m}\left|\eta_{c r}\right|_{\max }}{E I_{m}\left|\eta_{c r}^{\prime \prime}\right|_{m}}
$$

where

$$
e_{0 d, m}=\alpha\left(\bar{\lambda}_{m}-\bar{\lambda}_{0}\right) \frac{M_{R k, m}}{N_{R k, m}} \frac{1-\frac{\bar{\lambda}_{m}{ }^{2} \chi}{\gamma_{M 1}}}{1-\bar{\lambda}_{m}{ }^{2} \chi}=e_{0 k} \delta_{e}
$$

is the design value of bow imperfection for the equivalent member; $m$ is the index of the critical cross-section;

$$
\bar{\lambda}_{m}=\sqrt{\frac{N_{R k, m}}{N_{c r, m}}}
$$

is the relative slenderness; $M_{R k, m}$ is the characteristic bending resistance of the critical cross-section; $N_{R k, m}$ is the characteristic axial force resistance of the critical crosssection; $\chi$ is the reduction factor for the relevant buckling curve and relative slenderness; $N_{c r, m}$ is the elastic critical force, i.e. the axial force in the critical crosssection $m$ under the critical loading of the structure; $\eta_{c r}$ is the elastic critical buckling mode; $\left|\eta_{c r}^{\prime \prime}\right|_{m}$ second derivative of the elastic critical buckling mode in critical crosssection.

Presented explanation covers only a small part of the whole knowledge about the use of the EUGLI imperfection procedure ([1], [2] clause 5.3 .2 (11) procedure). 
Therefore, for full understanding of EUGLI imperfection, it is recommended to study the background in [3].

\section{Iteration procedure (matrix arranged calculation procedure)}

An iterative approach is used in the EUGLI imperfection method for the determination of the structure's critical cross-section. In the first iteration step, it is necessary to estimate the position of this cross-section. In the calculation of EUGLI imperfection amplitude (1), this cross-section's parameters are used. The iteration procedure is finished when the position of the cross-section with maximal utilization percentage (by means of EUGLI imperfection method) calculated by the program is the same in two consecutive iterations. This cross-section is called the critical cross-section.

However, in automatic computer calculations, it is possible that this iterative approach does not reach convergence - the program enters a never-ending cycle. This problem was first time ascribed to unsuitable programming code, but in previous research there was discovered, that in some structures it is not possible to find critical cross-section by means of EUGLI imperfection method (this problem is described in following chapters).

To avoid the iteration procedure, it is possible to use the so-called 'brute force method' (mass iteration method). Every cross-section on the structure is first considered as critical cross-section with parameters used for the EUGLI imperfection amplitude. The best way to align the obtained results is to use a matrix form. Values in the cells along the rows represent the EUGLI imperfection method utilization ratios of the structure in cross-sections $j$, where the row $i$ obtains the imperfection amplitude based on the parameters of the cross-section $i$ ( $i$ and $j$ are defining the position in the matrix). Values on the matrix diagonal $(i=j)$ represent the utilization factors in cross-sections used for defining the EUGLI imperfection amplitude. If the maximal utilization ratio in a row lies on the matrix diagonal, $i=j$ is the definition of critical cross-section position. Critical cross-section can only be found by means of the $2^{\text {nd }}$ order axial force and $2^{\text {nd }}$ order bending moment caused by the deformation of the structure into an imperfect shape. The $2^{\text {nd }}$ order theory is used at all stages of calculation and therefore it is possible to add the values of the bending moment caused by the external loading and bending moment caused by the structure deformed into an imperfect shape at the end of the calculation procedure. By programming, it is necessary to ensure that the amplitude (based on its parameters) is set up for each cross-section $i$. For the amplitude, the structural utilization of cross-sections $j$ is evaluated and written into the row $j$. Part of the computer program designed to find the critical cross-section is based on finding the matrix cell with maximal utilization factor on the matrix diagonal (by means of the EUGLI method). All rows must be checked. You can find a part of utilization matrix in Table I with short explanation.

Arrows in Table I are representing possible iteration steps (if there is not used EUGLI imperfection method utilization matrix). Iteration process can be described as follows: 
1) First cross-section (considered as critical cross-section) is chosen in crosssection No. 1, but the highest utilization ratio of the structure (according to EUGLI imperfection method calculation) is in cross-section No. 9;

2) Second cross-section is chosen in cross-section No. 9, but the highest utilization ratio is in cross-section No. 3;

3) Third cross-section is chosen in cross-section No. 3, but the highest utilization ratio is in cross-section No. 6;

4) Fourth cross-section is chosen in cross-section No. 6, but the highest utilization ratio is in cross-section No. 5;

5) Cross-section No. 5 is critical cross-section of the structure (in the whole row is utilization ratio in cross-section No. 5 the highest).

Table I

Utilization matrix (part), $j$ - utilization ratios of the structure in cross-sections $j$ (row represents utilization along the structure), $i$ - obtains the imperfection amplitude based on the parameters of the cross-section $i$ (lies on the diagonal of utilization matrix)

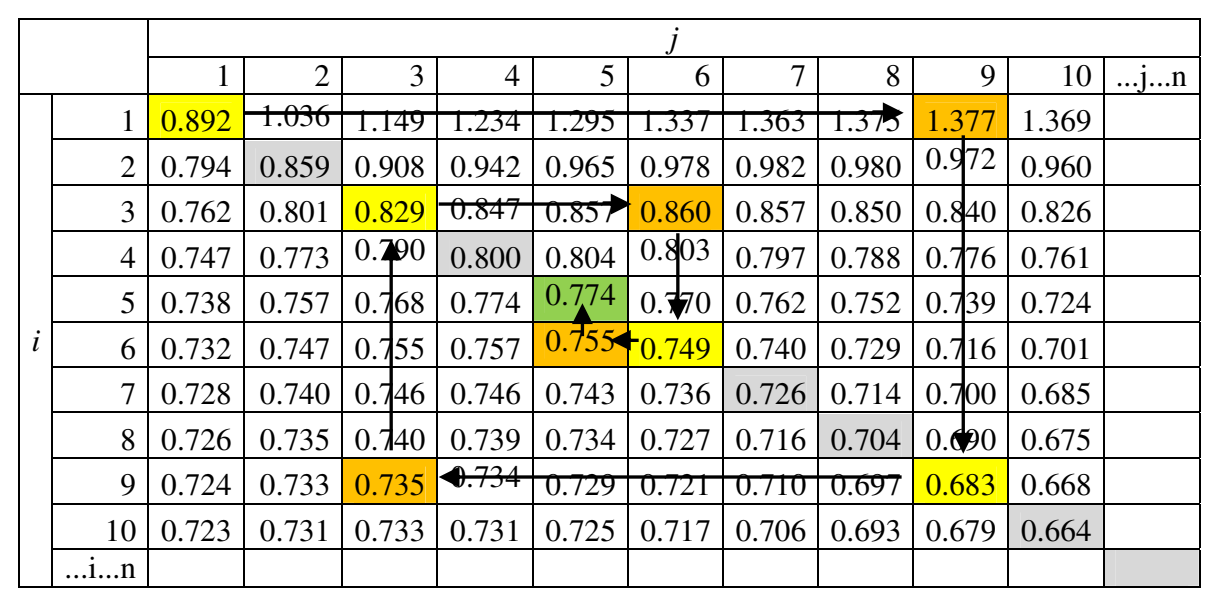

\section{Discovered obstacle}

As was mentioned in Paragraph 2 the main discovered obstacle during research on EUGLI imperfection method calculation procedure was the problem of not reaching critical cross-section. This problem occurs mainly on following examined structures:

- Columns with step change in cross-sectional parameters and step change in axial force along the members (example is given in this paper);

- Columns with step change in axial force, cross-sectional parameters are uniform;

- Columns of frames with step change in cross-sectional parameters and step change in axial force along the members (columns); 
- Frames with thick columns and thin rafters (example: hinged one-tract frame; $h=7 \mathrm{~m} ; L=10 \mathrm{~m}$; column: HEA320; rafter: HEA140; S355; elastic crosssectional parameters).

There were other cases where the critical cross-section was not found by means of EUGLI imperfection method, but it is necessary to mention, that a huge part of these solved cases were structures without any possible practical use according to chosen cross-sectional parameters.

The best way how to explain the occurred problem is to demonstrate it on working example (Fig. 1 - Fig. 4) of fixed-free column with step change in cross-sectional parameters and axial force. Table II represents utilization matrix of presented column example. In this example 15 elements on the structure are used (small number but in this case there is no need to use more elements problem withstands anyway).

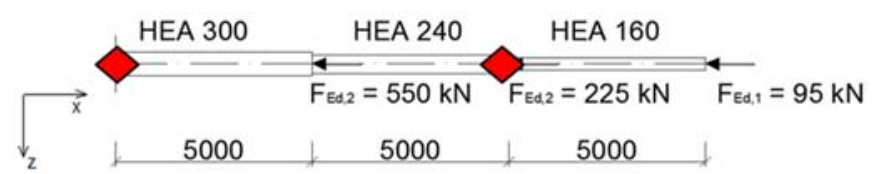

Fig. 1. Fixed-free column scheme with position of 'two possible' critical cross-sections $\left(\mathrm{S} 355 ; \gamma_{M 1}=1.0\right.$; elastic cross-sectional parameters)

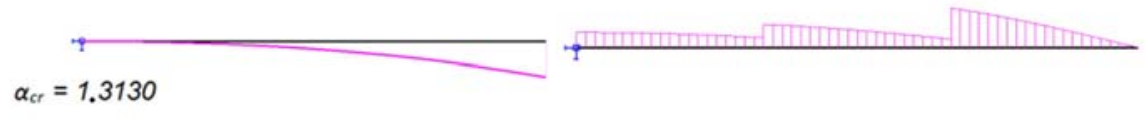

Fig. 2. $1^{\text {st }}$ buckling mode $\left(\eta_{c r}(x)\right)$ and critical factor, second derivative of $1^{\text {st }}$ b. m. $\left(\eta_{c r}^{\prime \prime}(x)\right)$

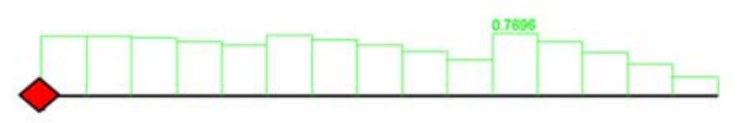

Fig. 3. Utilization of column and position of critical cross-section 'No. 1' (0.7696) (Imperfection amplitude $\eta_{\text {init, }, \text {, max }}=230.1 \mathrm{~mm}$ )

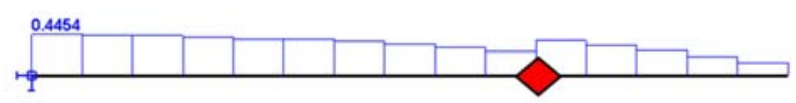

Fig. 4. Utilization of column and position of critical cross-section 'No. 11' (0.4454) (Imperfection amplitude $\eta_{\text {init,m,max }}=100.9 \mathrm{~mm}$ )

The iteration cycle in this example is described:

1) First considered critical cross-section is cross-section No. 3, the highest utilization ratio is in cross-section No. 11; 
2) Second considered critical cross-section is cross-section No. 11, the highest utilization ratio is in cross-section No. 1;

3) Third considered critical cross-section is cross-section No. 1, the highest utilization ratio is in cross-section No. 11;

4) This iteration enters never ending cycle.

\section{Table II}

Utilization matrix (part) and possible iteration cycles (only diagonal values can serve as possible solutions of the EUGLI imperfection method). Critical cross-section does not exist

\begin{tabular}{|r|r|r|r|r|r|r|r|r|}
\hline & 1 & 2 & 3 & 4 & 10 & 11 & 12 & 15 \\
\hline 1 & 0.737 & -0.729 & 0.706 & 0.69 & 0.44 & 0.770 & 0.662 & 0.231 \\
\hline 2 & 0.744 & 0.737 & 0.713 & 0.675 & 0.452 & 0.780 & 0.671 & 0.234 \\
\hline 3 & 0.769 & 0.761 & 0.737 & 0.697 & 0.46 & $0 . \$ 14$ & 0.699 & 0.241 \\
\hline 4 & 0.815 & 0.806 & 0.780 & 0.737 & 0.497 & $0 . \$ 75$ & 0.751 & 0.256 \\
\hline 10 & 0.836 & 0.827 & 0.800 & 0.755 & 0.510 & $0 . \$ 04$ & 0.775 & 0.262 \\
\hline 11 & 0.445 & -0.442 & 0.432 & 0.416 & 0.262 & 0.376 & 0.329 & 0.140 \\
\hline 12 & 0.487 & 0.483 & 0.471 & 0.452 & 0.288 & 0.432 & 0.376 & 0.153 \\
\hline 15 & 1.201 & 1.187 & 1.143 & 1.072 & 0.742 & 1.397 & 1.193 & 0.376 \\
\hline
\end{tabular}

\section{Proposed solution}

During numerical research, three different methods for solution of discovered problem were proposed (critical cross-section was not found). One of them is to choose between cross-sections shown in Fig. 1. Second approach is based on considering both cross-sections. The third one is based on finding a section of 'average value'. The lastmentioned approach shows (by author's opinion) the most reasonable results. In Table III solution according the method of finding a section of 'average value' is shown. However, none of these three methods satisfies the main idea of EUGLI imperfection calculation procedure.

\section{Table III}

EUGLI utilization matrix (part) calculated with 'average value' critical cross-section. A crosssection, which gives basically the same utilization values in both cross-sections No. 1 and No. 11 was chosen (these two cross-sections have the highest utilization ratio in the whole row)

\begin{tabular}{|r|r|r|r|r|r|r|r|r|r|}
\hline & 1 & 2 & 3 & 4 & 8 & 10 & 11 & 12 & 15 \\
\hline 1 & 0.737 & 0.729 & 0.706 & 0.669 & 0.623 & 0.447 & 0.770 & 0.662 & 0.231 \\
\hline 2 & 0.744 & 0.737 & 0.713 & 0.675 & 0.630 & 0.452 & 0.780 & 0.671 & 0.234 \\
\hline 3 & 0.769 & 0.761 & 0.737 & 0.697 & 0.654 & 0.468 & 0.814 & 0.699 & 0.241 \\
\hline 4 & 0.815 & 0.806 & 0.780 & 0.737 & 0.699 & 0.497 & 0.875 & 0.751 & 0.256 \\
\hline 8 & 0.621 & 0.615 & 0.597 & 0.568 & 0.510 & 0.374 & 0.613 & 0.530 & 0.195 \\
\hline 10 & 0.836 & 0.827 & 0.800 & 0.755 & 0.719 & 0.510 & 0.904 & 0.775 & 0.262 \\
\hline 11 & 0.445 & 0.442 & 0.432 & 0.416 & 0.339 & 0.262 & 0.376 & 0.329 & 0.140 \\
\hline 12 & 0.487 & 0.483 & 0.471 & 0.452 & 0.379 & 0.288 & 0.432 & 0.376 & 0.153 \\
\hline 15 & 1.201 & 1.187 & 1.143 & 1.072 & 1.075 & 0.742 & 1.397 & 1.193 & 0.376 \\
\hline
\end{tabular}


For better understanding of this problem many similar cases with small changes in cross-sectional parameters or axial forces were recalculated to investigate, why this problem occurs. In Table $I V$ short parametric study on presented example is shown. $F_{s}$ is the middle load; $\alpha_{c r}$ is the critical factor of the structure; $P 1$ is the position of the 'critical cross-section No. 1' on the $x$-axis of the column; $P 2$ is the position of the 'critical cross-section No. 2' on the $x$-axis on the column; $P V$ is the final position of the selected critical cross-section (used 'average value'); $\eta_{\text {init,m, max }}$ is the amplitude value of EUGLI imperfection and $U_{\max }$ is the maximal utilization value by means of EUGLI method. It is obvious that if $P 1=P 2$, structure has critical cross-section. If this condition is not met, the critical cross-section does not exist.

\section{Table IV}

Position of critical cross-section and other parameters - middle force is changed

\begin{tabular}{|c|c|c|c|c|c|c|c|}
\hline Case & $\mathrm{F}_{\mathrm{S}}$ & $\alpha_{\mathrm{cr}}$ & $\mathrm{P} 1$ & $\mathrm{P} 2$ & $\mathrm{PV}$ & $\eta_{\text {init,max }}$ & $\mathrm{U}_{\max }$ \\
\hline 1 & $100 \mathrm{kN}$ & 1.5854 & $10 \mathrm{~m}$ & $0 \mathrm{~m}$ & $11.75 \mathrm{~m}$ & $119.66 \mathrm{~mm}$ & 0.3173 \\
2 & $125 \mathrm{kN}$ & 1.5260 & $10 \mathrm{~m}$ & $0 \mathrm{~m}$ & $11.95 \mathrm{~m}$ & $131.16 \mathrm{~mm}$ & 0.3561 \\
3 & $150 \mathrm{kN}$ & 1.4690 & $10 \mathrm{~m}$ & $0 \mathrm{~m}$ & $5 \mathrm{~m}$ & $142.80 \mathrm{~mm}$ & 0.4026 \\
4 & $175 \mathrm{kN}$ & 1.4144 & $10 \mathrm{~m}$ & $0 \mathrm{~m}$ & $6 \mathrm{~m}$ & $155.87 \mathrm{~mm}$ & 0.4615 \\
5 & $200 \mathrm{kN}$ & 1.3624 & $10 \mathrm{~m}$ & $0 \mathrm{~m}$ & $12.45 \mathrm{~m}$ & $171.43 \mathrm{~mm}$ & 0.5393 \\
6 & $225 \mathrm{kN}$ & 1.3130 & $10 \mathrm{~m}$ & $0 \mathrm{~m}$ & $7.35 \mathrm{~m}$ & $189.80 \mathrm{~mm}$ & 0.6445 \\
7 & $250 \mathrm{kN}$ & 1.2662 & $5 \mathrm{~m}$ & $0 \mathrm{~m}$ & $6.45 \mathrm{~m}$ & $167.35 \mathrm{~mm}$ & 0.6723 \\
8 & $275 \mathrm{kN}$ & 1.2218 & $5 \mathrm{~m}$ & $5 \mathrm{~m}$ & $5 \mathrm{~m}$ & $144.10 \mathrm{~mm}$ & 0.7089 \\
9 & $300 \mathrm{kN}$ & 1.1798 & $5 \mathrm{~m}$ & $5 \mathrm{~m}$ & $5 \mathrm{~m}$ & $143.94 \mathrm{~mm}$ & 0.8617 \\
10 & $325 \mathrm{kN}$ & 1.1401 & $5 \mathrm{~m}$ & $5 \mathrm{~m}$ & $5 \mathrm{~m}$ & $143.73 \mathrm{~mm}$ & 1.0854 \\
\hline
\end{tabular}

Case No. 6 is solved example (there are used 300 elements on the structure, therefore the inaccuracy with results shown in Table III). In cases No. 1-7 the critical cross-section is not found. As seen on the Table IV (case No. 7 and No. 8) only small change in axial force causes, that the critical cross-section is found. In EUGLI imperfection method is very important to find out precise position of critical crosssection because of amplitude calculation, all of the parameters shown in formulae (1) are depending on position of critical cross-section.

\section{Short recapitulation and future experiment proposal}

All presented results are only a small part of the whole numerical research done for author's dissertation $\mathrm{PhD}$ Thesis [11]. Some information about similar topic can be found in [12]-[18]. Examples not only for in plane buckling, but for Flexural-Torsional Buckling (FTB) and Lateral-Torsional Buckling (LTB) were calculated too. Some information about this calculation procedure is published in [19] and [20], based on research papers [21] and [22]. During research on EUGLI imperfection method it was necessary to broaden knowledge not only from one discipline (stability), but many important topics were learned from fields like structural dynamics, FEM analysis, mathematics and programming. Acquired programming skills and developed computer program were also used in research [23], [24]. 
Research presented in this paper is one of numerous researches based on topic of stability, which were done in Department of Steel and Timber Structures, Faculty of Civil Engineering, Slovak University of Technology in Bratislava [25], [26].

In recent time there is future experimental research on round and hexagonal tubes (Fig. 5) proposed, where we would like to obtain imperfection parameter $\alpha$ through EUGLI imperfection procedure and to prove by experimental research if it is possible or not.

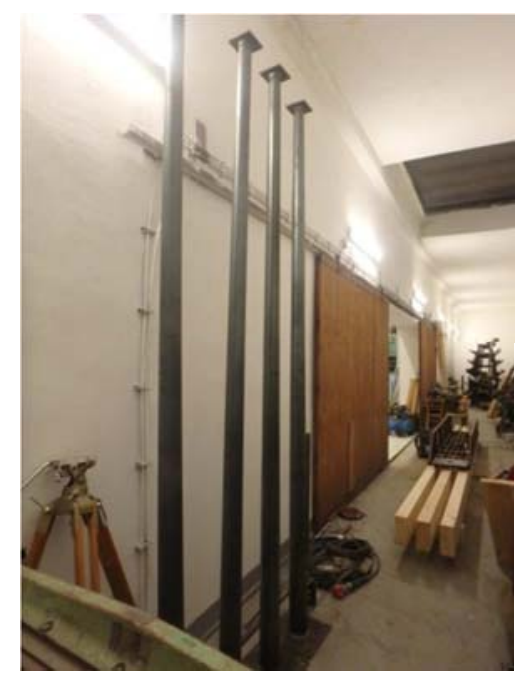

Fig. 5. Specimens for future experimental research

\section{Conclusion}

Regardless of the obstacle (critical cross-section of the structure is not found) discovered in the EUGLI imperfection calculation procedure, it can be used very effectively on different types of structures (columns with changeable cross-sectional parameters along height, frames, arches, and special shape plane structures). The advantage of EUGLI imperfection by evaluation of mentioned structures is the universality of its use.

In engineering practice is not possible to measure imperfections on so many different types of structures, EUGLI imperfection uses connection with equivalent member method (based on research on variety types of uniform cross-section column samples) and applies this imperfection on mentioned structures. The question why to use such imperfection amplitude for elastic critical buckling mode imperfection shape is not relevant. EUGLI imperfection is one of the possibilities how to get out of this problem, the other way is to measure real life structures and propose other method based on these measurements.

The EUGLI imperfection has not been implemented into commercial civil engineering computer programs. The $2^{\text {nd }}$ order theory calculation is basically the 
standard procedure in programs; implementation of the EUGLI imperfection calculation procedure represents only a small amount of programming code. Two of the most used commercial civil engineering programs in Slovakia Scia Engineer and Dlubal (RFEM, RSTAB) have the possibility to use imperfection in the shape of elastic critical buckling mode, but the amplitude of such imperfection must be set by user. Presented computer program demonstrates this possibility.

\section{Acknowledgements}

The author would like to express thanks to the Grant agency of the Ministry of Education, Science, Research and Sports of the Slovak Republic for providing a grant from the research program VEGA Nr. 41/0747/16.

\section{References}

[1] EN 1993-1-1, 2005 Eurocode 3, Design of steel structures, Part 1-1, General rules and rules for buildings, 2005.

[2] EN 1999-1-1, 2005 Eurocode 9, Design of aluminum structures, Part 1-1, General structural rules, 2005.

[3] Chladný E, Štujberová M. Frames with unique global and local imperfection in the shape of elastic buckling mode, (Part 1, Part 2), Stahlbau, Vol. 82, No. 8, 2013, pp. 609-617; Vol. 82, No. 9, 2013, pp. 684-694.

[4] Baláž I. Determination of the flexural buckling resistance of frames with members with non-uniform cross-sections and non-uniform axial compression forces, Proceedings of the 34th Meeting of Experts on Steel Structures, Pezinok, Slovakia, 16-17 October 2008, pp. 17-22.

[5] Dalemulle M. Buckling resistance of arches in their plane, (in Slovak) PhD Thesis, Slovak University of Technology in Bratislava, 2013.

[6] Kovač M. Buckling resistance of metal members and frames, Applications of new methods from Eurocodes, (in Slovak), PhD Thesis, Slovak University of Technology in Bratislava, 2012.

[7] Papp F. Buckling assessment of steel members trough overall imperfection method, Engineering Structures, Vol. 106, 2016, pp. 124-136.

[8] Mathworks, Programming language MATLAB v. 2009.

[9] Brodniansky J. Kováč M. Application of EUGLI imperfection for assessment of members and frames with $4^{\text {th }}$ class cross-section, International Masaryk Conference for PhD. Students and Young Researchers, Hradec Králové, Česká Republika, 15-19 December 2014, Vol. V, pp. 3728-3737.

[10] Brodniansky J. $2^{\text {nd }}$ order structural analysis with imperfection according 5.3.2 (11) EN 1999-1-1 (method for computer analysis), eConference of Doctoral Students and Young Researcher, Bratislava, Slovakia, 20-24 July 2015, pp. 35-42.

[11] Brodniansky J. Resistance of thin-walled members and structures using imperfection in the shape of the elastic critical buckling mode, PhD Thesis, Slovak University of Technology in Bratislava, 2016.

[12] Ároch R., Brodniansky J. Comparison of different Eurocode verifications of a thin-walled member portal frame, Proceedings of the International Colloquim on Stability and Ductility of Steel Structures, SDSS '2016, Timisoara, Romania, 30 May-1 June 2016, pp. 275-282. 
[13] Brodniansky J., Balcierák L', Duchoň V., Katona O. Numerical validation of EUGLI imperfection method for columns with varying cross-sectional parameters, Interdisciplinarity in Theory and Practice, No. 10, 2016, pp. 321-326.

[14] Brodniansky J. Equivalent imperfection for columns and beams (FTB problem, LTB problem) Proceedings of 18th International Conference of Posgraduate Students JUNIORSTAV, Brno, Czech Republic, 28 January 2016, p. 135.

[15] Brodniansky J. EUGLI imperfection for axially loaded columns and beams under influence of bending moment, 6. Mezinárodní Masarykova konference pro doktorandy a mladé vědecké pracovníky MMK 2015, sborník příspěvků z mezinárodní vědecké konference, Hradec Králové, Česká Republika, 14-18 December 2015, pp. 2516-2523.

[16] Kala Z. Global sensitivity analysis in stability problems of steel frame structures, Journal of Civil Engineering and Management, Vol. 22, 2016, pp. 417-424.

[17] Kala Z. Application of global sensitivity analysis methods in civil engineering, 25th European Safety and Reliability Conference, ESREL, Zurich, Swaziland, 7-10 September 2015, pp. 2541-2545.

[18] Giżejowski M. A., Szczerba R., Gajewski M. D., Stachura Z. Buckling resistance assessment of steel I-section beam-columns not susceptible to LT-buckling, Archives of Civil and Mechanical Engineering, Vol. 17, 2017, pp. 205-221.

[19] Dallemule M. Buckling mode as an imperfection in arch structures, Pollack Periodica, Vol. 8, No. 2, 2013, pp. 29-40.

[20] Baláž I., Koleková Y. Bending moments due to elastic buckling mode applied as uniform global and local initial imperfection of frames, Procedia Engineering, 23rd Czech and Slovak International Conference on Steel Structures and Bridges 2012, Podbanske, Slovakia, 26-28 September 2012, Vol. 40, pp. 32-37.

[21] Agüero A., Palláres L., Palláres F. J. Equivalent geometric imperfection definition in steel structures sensitive to flexural and/or torsional buckling due to compression, Engineering Structures, Vol. 96, 2015, pp. 160-177.

[22] Agüero A., Palláres L., Palláres F. J. Equivalent geometric imperfection definition in steel structures sensitive to lateral torsional buckling due to bending moment, Engineering Structures, Vol. 96, 2015, pp. 41-55.

[23] Horáček M., Melcher J. Lateral torsional buckling of thin-walled cold-formed steel beams with web holes, Finite element analysis, Applied Mechanics and Materials, Vol. 467, 2013, pp. 425-430.

[24] Horáček M., Melcher J., Pešek O., Brodniansky J. Focusing on problem of lateral torsional buckling of beams with web holes, Procedia Engineering, World Multidisciplinary Civil Engineering-Architecture-Urban Planning Symposium, WMCAUS 2016, Vol. 161, Prague, Czech Republic, 13-17 June 2016, pp. 549-555.

[25] Ilanovsky V. Assesment of bending moment resistance of girders with corrugated web, Pollack Periodica, Vol. 10, No. 2, 2015, pp. 35-44.

[26] Kováč M. Lateral-torsional buckling of web-tapered I-beams. 1D and 3D FEM approach, Procedia Engineering, 23rd Czech and Slovak International Conference on Steel Structures and Bridges 2012, Podbanske, Slovakia, 26-28 September 2012, Vol. 40, pp. 217-222. 